\title{
EFFECT OF DIFFERENT SURFACE TREATMENT MODALITIES ON SURFACE ROUGHNESS AND SHEAR BOND STRENGTH OF ORTHODONTIC MOLAR TUBES TO LITHIUM DISILICATE CERAMICS
}

\author{
Rania E Bayoumi *, Sara M.El-Kabbany ${ }^{* *}$ and Nevin $\mathrm{Gad}^{* * *}$
}

\begin{abstract}
Objectives; This study aimed to evaluate the effect of different surface treatment modalities on surface roughness(SR) and shear bond strength (SBS) of orthodontic molar tubes to lithium disilicate (IPS e-max CAD/CAM, Ivoclar Vivadent) ceramic and human enamel using different adhesives.
\end{abstract}

Materials and methods: A total of 150 e-max specimens were randomly divided into five groups ( $\mathrm{n}=30)$ according to the method of surface treatment used. In group I (control group): no surface treatment, group II: sandblasting with $50 \mu \mathrm{m} \mathrm{Al}_{2} \mathrm{O}_{3}$ slurry particles, group III: etching with hydrofluoric acid $9.6 \%$, group IV: etching with hydrofluoric acid $4.5 \%$ and group V: etching with phosphoric acid $37 \%$. Further random distribution of e-max specimens into subgroups was performed according to the type of adhesive used (One coat 7, G-Premio Bond and Ortho solo). The surface roughness was investigated using digital profilometer and atomic force microscopy (AFM). Microstructural analysis was conducted using scanning electron microscope (SEM).The SBS was measured using universal testing machine. Results were statistically analyzed.

Results: Results showed that the sandblasting group had significantly highest surface roughness, while the lowest value was recorded in the Phosphoric acid 37\% group. Furthermore, sandblasted group showed the highest SBS, while control group showed the lowest SBS. Strong positive correlation was found between the surface roughness of lithium disilicate and shear bond strength. Meanwhile, no significant differences were found between different adhesive agents use.

Conclusions: Shear bond strength was highly affected by the surface roughness which subsequently controlled by the surface treatment modalities and not by the adhesives types. Hydrofluoric acid $4.5 \%$ and phosphoric acid $37 \%$ are recommended techniques for reliable bond strength between metal tubes and lithium disilicate ceramic.

KEYWORDS: Lithium disilicate ceramics; orthodontic molar tubes; shear bond strength; silane treatment; surface tretment; surface roughnes

\footnotetext{
*Lecturer, Biomaterials Department, Faculty of Dentistry (girls), Al-Azhar University.

**Lecturer, Orthodontic Department, Faculty of Dentistry (girls), Al-Azhar University.

***Lecturer, Operative Dentistry Department Faculty of Dentistry (girls), Al -Azhar University.
} 


\section{INTRODUCTION}

Aesthetic demands of dental patients have attracted considerable attention to the use of ceramic restorations. Lithium disilicate-based ceramics are widely used as full ceramic restorations due to their high fracture toughness and excellent esthetic quality. However, they consist of amorphous matrix loaded with 60-70\% crystalline phase, which provide higher resistance to acid etching compared to feldspathic ceramics ${ }^{(1,2)}$.

Orthodontists frequently encounter patients who have one or more ceramic restorations. Bonding of orthodontic attachment to high crystalline content ceramics such as Lithium disilicate represents a great difficulty. ${ }^{(3)}$ The composite applied to ceramic without roughening the ceramic surface created too weak bond strength to bear forces necessary for orthodontic tooth movements. ${ }^{(4)}$

Several surface conditioning modalities either mechanically or chemically, have been advocated to increase the bond strength of orthodontic brackets to the ceramic surface to achieve durable bond strength. ${ }^{(5)}$ Mechanical roughening can be performed by sandblasting or by using a diamond bur. However, it has been proved that the mechanical alteration of the ceramic surfaces resulted in the development of microcracks and caused irreversible surface damage, compromising the integrity of crowns or bridges ${ }^{(6)}$ Concerning chemical treatment, many studies reported that phosphoric acid does not etch ceramic surfaces; however, phosphoric acid with silane coupling agents demonstrated sufficient bond strength. ${ }^{(7,8)}$ Moreover, acid etching with hydrofluoric acid (HF) can also be used to increase bond strength as it forms a micro-retentive etched pattern on the ceramic surface. It is commercially available in various concentrations but it is potent acid and it could traumatize the soft tissues and during its usage it requires careful isolation in working area. The lesion severity is directly related to its concentration and exposure time. ${ }^{(9-11)}$

To minimize dental inventory, dental manufacturers have introduced "Universal Adhesives" that include MDP (Methacryloyloxydecyl dihydrogen phosphate) monomer as an ingredient. The presence of a functional monomer (MDP) and subsequent application of silane give optimum adhesion results for both etchable and non-etchable ceramics in dentistry. In addition, universal adhesives can be used in a moist environment, due to the aqueous components contained in the primer. ${ }^{(12,13)}$ Meanwhile, silanization process results in a strong chemical bond between silicon dioxide surface of glass ceramics and resin cement matrix during polymerization. ${ }^{(14)}$

Selection of a safe surface treatment method and the best adhesive system that produce strong bond strength for orthodontic molar tubes on the ceramic surface became the main problem in the orthodontic attachment. The majority of studies evaluated the bond strength of orthodontic molar tubes bonded to feldspathic ceramics, whereas those concerned with other types of ceramics are limited. ${ }^{(15-17)}$

Thus, this study aimed to assess the effect of different surface treatments on the surface roughness of lithium disilicate. In addition, it evaluated the bond strength of orthodontic molar tubes to the ceramic when various adhesives were used. The null hypothesis states that surface treatment of lithium disilicate would not affect its shear bond strength with the orthodontic molar tubes.

\section{MATERIALS AND METHODS}

\section{Materials :}

Materials, chemical compositions and manufacturer used in this study are listed in table (1). 
TABLE (1) Materials Used in this Study

\begin{tabular}{|c|c|c|c|c|}
\hline Material & Brand Name & Chemical Composition & Lot Number & Manufacturer \\
\hline $\begin{array}{l}\text { Lithium disilicate } \\
\text { glass ceramic }\end{array}$ & IPS e.max CAD & $\begin{array}{l}\text { Lithium meta-silicate crystals with } \\
\text { approximately } 40 \% \text { crystals by } \\
\text { volume. Additional contents } \mathrm{Li}_{2} \mathrm{O} \text {, } \\
\qquad \mathrm{K}_{2} \mathrm{O}, \mathrm{MgO}, \mathrm{AL}_{2} \mathrm{O}_{3}, \mathrm{P}_{2} \mathrm{O}_{2}\end{array}$ & T35554 & $\begin{array}{c}\text { Ivoclar Vivadent, } \\
\text { Schaan, Lichtenstein }\end{array}$ \\
\hline \multirow{3}{*}{ Bonding agent } & $\begin{array}{l}\text { One coat } 7 \\
\text { universal bonding }\end{array}$ & $\begin{array}{l}\text { Methacrylates including } 10 \mathrm{MDP} \\
\text {-polyacrylic acid ,photoinitiator, } \\
\text { ethanol ,water }\end{array}$ & 120864 & $\begin{array}{l}\text { Coltène } \\
\text { Whaledent,Switzerland }\end{array}$ \\
\hline & $\begin{array}{l}\text { G-Premio Bond } \\
\text { universal bonding }\end{array}$ & $\begin{array}{l}\text { Monomers (4-META, MDP, MDTP), } \\
\text { acetone, dimethacrylate, phosphoric } \\
\text { acid ester monomer, dimethacrylates } \\
\text { component, photoinitiator, butylated } \\
\text { hydroxytoluene. }\end{array}$ & 1712142 & $\begin{array}{l}\text { GC Dental Products } \\
\text { Corp, Tokyo, Japan }\end{array}$ \\
\hline & $\begin{array}{l}\text { Ortho Solo } \\
\text { Universal sealant } \\
\text { and bond enhancer }\end{array}$ & $\begin{array}{l}\text { Ethyl alcohol,alkyl dimethacrylate } \\
\text { resins,barium aluminoborosilicate } \\
\text { glass, fumed silica,sodiumhexa } \\
\text { fluorosilicate }\end{array}$ & 5825533 & $\begin{array}{c}\text { Ormco- corporation, } \\
\text { Glendora,California, } \\
\text { USA }\end{array}$ \\
\hline $\begin{array}{l}\text { Hybrid Light cured } \\
\text { composite }\end{array}$ & GrenGloo $^{\mathrm{TM}}$ & $\begin{array}{c}\text { 20-38\% uncured methacrylate ester } \\
\text { monomers,inert mineral fillers, } \\
\text { fumed silica, activators and } \\
\text { preservative }\end{array}$ & 5799890 & $\begin{array}{l}\text { Ormco corporation } \\
\text { Glendora, California, } \\
\text { USA. }\end{array}$ \\
\hline Porcelain etching gel & Porc-Etch & $\begin{array}{l}9.6 \% \text { hydrofluoric acid, water, } \\
\text { thickener, surfactant and dye }\end{array}$ & 175181 & $\begin{array}{l}\text { Reliance Orthodontic } \\
\text { Products, Inc. Itasca, } \\
\text { Illinois, USA }\end{array}$ \\
\hline Ceramic etching gel & $\begin{array}{c}\text { IPS Ceramic } \\
\text { Etching Gel (Refill) }\end{array}$ & $\begin{array}{l}4.5 \% \text { hydrofluoric acid, water, } \\
\text { thickener, surfactant and dye }\end{array}$ & V37045 & $\begin{array}{l}\text { Ivoclar Vivadent, } \\
\text { Schaan, Lichtenstein }\end{array}$ \\
\hline Etching solution & Liquid Etch & $\begin{array}{l}37 \% \text { Phosphoric acid ,water, fumed } \\
\text { silica }\end{array}$ & $17 \mathrm{~J} 2 \mathrm{~A}$ & $\begin{array}{l}\text { Liquid Etch, Ormco, } \\
\text { USA }\end{array}$ \\
\hline Silane coupling agent & $\begin{array}{c}\text { Porcelain } \\
\text { Conditioner }\end{array}$ & $\begin{array}{c}<1 \% \text { aminosilano, } 70-80 \% \text { etanol } \\
\text { and } 20-30 \% \text { water }\end{array}$ & 174643 & $\begin{array}{l}\text { Reliance Orthodontic } \\
\text { Products, Inc. Itasca, } \\
\text { Illinois, USA }\end{array}$ \\
\hline Buccal Tubes & $\begin{array}{l}\text { OrthoPro Trumpax } \\
\text { Buccal Tubes }\end{array}$ & $\begin{array}{l}\text { Metal Injection Molded (MIM) Alloy } \\
\text { of chromium and nickel with an } \\
\text { average base surface area of } 29 \mathrm{~mm}^{2}\end{array}$ & FL34234 & $\begin{array}{l}\text { Ortho Pro Dent LLC, } \\
\text { Sarasota, U.S.A }\end{array}$ \\
\hline
\end{tabular}

\section{Methods:}

Regarding the sample size calculation (power analysis), its performance depends on certain statistical measurements plus the effective size which is the difference between the groups to be compared regarding the primary outcome. Using $\alpha$ level of 0.05 and $80 \%$ power and effect size is equal to 0.72 was yield to a sample size of 6 samples per group, 10 samples per group were used to gain extra power

\section{Ceramic specimens' preparation:}

A total of 150 ceramic specimens were prepared and used to test the effect of different ceramic treatment modalities on surface roughness and shear bond strength. 
Eleven blocks of lithium disilicate (IPS e-max) were sectioned longitudinally using Isomet 4000 precision saw (Buehler Ltd ,Lake Bluff, IL, USA) under water coolant each one into two equal blocks, then sectioned horizontally into 14 rectangular specimens $(10 \mathrm{~mm} \times 8 \mathrm{~mm} \times 1.2 \mathrm{~mm})$. Each specimen was placed in a Vita vacumat (Vita Zahnfabrik) furnace at $840-850^{\circ} \mathrm{C}$ according to the manufacturer's instructions to complete the crystallization process and to establish a uniform surface prior to glazing. Then, the specimens were mounted in $2 \mathrm{~cm}$ $\times 1 \mathrm{~cm} \times 2 \mathrm{~cm}$ Teflon mold filled with auto polymerizing acrylic resin (Acrostone, Cold cure, Egypt).

A total of 150 specimens were divided into five main groups ( $n=30 /$ group) according to the surface treatment. Each group was subsequently subdivided into three subgroups ( $\mathrm{n}=10$ /group) according to the type of adhesive

Group I: The specimens were not subjected to surface treatment.

Group II: The specimens were sandblasted with $50 \mu \mathrm{m} \mathrm{Al}_{2} \mathrm{O}_{3}$ slurry particles (Renfort basic classic ,Gmbh, Germany) for 10 second with distance 10 $\mathrm{mm}$ and air pressure of 2.5 bars.

Group III: The specimens were etched with $9.6 \%$ hydrofluoric acid gel for $3 \mathrm{~min}$.

Group IV: The specimens were etched with $4.5 \%$ hydrofluoric acid gel for $3 \mathrm{~min}$.

Group V: The specimens were etched with $37 \%$ orthophosphoric acid for $4 \mathrm{~min}$.

After acid removal with a cotton roller; either HF or phosphoric acid, specimens were rinsed for $20 \mathrm{~s}$ and dried with oil-free air for $15 \mathrm{~s}$.

\section{Surface Roughness:}

The micro- roughness of the specimens of each group was determined with a digital profilometer with a diamond stylus ( $5 \mu \mathrm{m}$ radius) across the specimen surface under a constant load of $4 \mathrm{mN}$ (0.4 gf) and scanning duration was 10s (Mitotoyo Surf Test SJ 201 P/M; Mitutoyo Corp, Takatsu-ku,
Japan). The surface roughness value ( $\mathrm{Ra}$ ) in $\mu \mathrm{m}$ of each specimen was recorded as numerical values.

\section{Surface and microstructural analyses:}

Detailed 3D topographical analysis for the treated surfaces was performed using Atomic Force Microscope (AFM) (Thermomicroscope, Autoprobe $\mathrm{CP}$ reasearch, scanner 100M, USA). Representative e.max specimens for each group were selected for the thorough examination. The specimen's surface was $3 \mathrm{D}$ imaged $(50 \mu \mathrm{m} \times 50 \mu \mathrm{m})$ in contact mode in air at room temperature. The force of the cantilever tip on the specimens' surfaces was kept constant during scanning in the range of $2.5 \mathrm{Nn}$. The scanned area was $25 \times 25 \mu \mathrm{m}$. The data were recorded by computer software.

For microstructure analysis, three representative e.max specimens from each group were scanned using Environmental Scanning Electron Microscope (ESEM) (QuantaTM 250 FEG, FEI Company, Netherlands). The specimens were mounted on a copper holder and images were captured at magnification 500x and 2000x using an accelerating voltage of $20-25 \mathrm{kV}$.

\section{Bonding Procedure.}

After determination of (Ra), the surfaces of e.max specimen's surface were rinsed by distilled water for $20 \mathrm{~s}$ and dried with oil-free air for $15 \mathrm{~s}$. Specimens $(\mathrm{n}=30)$ were randomly assigned into three subgroups ( $n=10 /$ subgroup) according to the used adhesive bonding agent.

\section{Subgroup A: One coat 7 universal bonding}

One coat 7 bonding agent was applied to the treated ceramic surface using a foam pellet, the surface was rubbed for $20 \mathrm{~s}$ and gently dried with oil-free air for $5 \mathrm{~s}$. All of the samples were light cured for 20s with a visible light-curing unit (LED Bluephase C5, Ivoclar, Vivadent, $500 \mathrm{~mW} / \mathrm{cm} 2$ )

Subgroup B: G-Premio Bond universal bonding

G- Premio Bond was applied to ceramic surfaces and left for $10 \mathrm{sec}$ then air dried for $5 \mathrm{sec}$. All of the samples were light cured for 10s. 
Subgroup C: Ortho Solo universal bonding

A thin coat of Ortho Solo ${ }^{\mathrm{TM}}$ was applied to the surface and left wet without light curing.

Then, the silane conditioner material was applied to e.max surfaces with a brush and allowed to dry for $60 \mathrm{~s}$ and air dried for 30s for all subgroup. To standardize the area of adhesion of the tube, square stickers with an internal opening of $8 \times 4 \mathrm{~mm}$ were fixed on the conditioned surface. Sufficient pressure was applied on the tubes to squeeze excess adhesive then, the extruded material around the bracket margins was carefully removed using a hand instrument. The adhesive paste was then cured with a visible light-curing unit for $15 \mathrm{~s}$ on the mesial and $15 \mathrm{~s}$ on the distal side. Specimens were stored in distilled water at $37 \pm 2{ }^{\circ} \mathrm{C}$ for $24 \mathrm{~h}$. Then, they were thermocycled between 5 and $55^{\circ} \mathrm{C}$ for 3000 cycles before testing of the bond strength.

\section{Enamel specimens preparation:}

Thirty freshly extracted human wisdom teeth were selected to test the effect of different universal adhesive on shear strength to the enamel. Teeth were obtained from patients with age range of 2530 years. They were carefully inspected to be caries and defect-free, and were cleaned by hand scaler instrument (Scaler 10A, NOVA instruments Ltd, Berkshire, UK) to remove attached soft and hard tissue. Then, teeth were stored in normal saline at room temperature at $25-30^{\circ} \mathrm{C}$ and the storage solution was changed periodically to inhibit the growth of microbial pathogens. The buccal surface was polished with fluoride free pumice slurry using rubber cup mounted on a slow speed hand piece. Finally, teeth were rinsed with distilled water and dried with an oil-free air syringe.

\section{Mounting of teeth in acrylic blocks:}

Teeth were mounted in self-cured acrylic resin blocks. They were centered in the blocks with their long axis parallel to the base of the blocks such that buccal surface was exposed to be treated and bonded. Later, the mounted teeth in their blocks were stored in distilled water at room temperature for $24 \mathrm{~h}$ before subjecting to treatment procedure.

The enamel of buccal surface was etched with $37 \%$ phosphoric acid for 30s, thoroughly rinsed with water for $15 \mathrm{~s}$, air dried for $5 \mathrm{~s}$ and checked for the chalky white appearance. Teeth blocks were divided into three groups ( $n=10 /$ group) according to the used adhesive bonding agent. Then the procedures were completed identical to those previously described in bonding the orthodontic tubes to the ceramic surfaces. To standardize the area of adhesion of the tube on the enamel surface the mesial opening of the tube was placed below mesiobuccal cusp of the molor at the correct vertical height. The whole bonding procedure was carried out by a single operator to avoid inter-operator variation. All the specimens were stored in distilled water at $37 \pm 2^{\circ} \mathrm{C}$ for $24 \mathrm{~h}$ and thermocycled.

\section{Shear Bond Strength(SBS) Evaluation:}

Acrylic resin block was positioned, stabilized and fixed in place with screws. A chisel blade was attached to the upper movable compartment of the Universal Testing Machine. The blade was adjusted at the buccal tube base/tooth (or at the buccal tube base/e-max ceramic) interfaces at a cross-head speed of $0.5 \mathrm{~mm} / \mathrm{min}$ till fracture. The force required for debonding was recorded in Newtons (N) and divided by the mean surface area of the brackets $\left(29 \mathrm{~mm}^{2}\right)$. The length and width of the buccal tube base was measured using digital caliper (APT, 0-150 mm, Japan) with accuracy of $0.01 \mathrm{~mm}$. $^{(18)}$

Shear Bond strength $(\mathrm{MPa})=($ Force $(\mathrm{N})) /$ (Surface Area of bracket $\left(\mathrm{mm}^{2}\right)$ )

\section{Adhesive remnant index (ARI) evaluation:}

The ARI was used to evaluate the amount of remaining adhesive on the substrates (e-max/tooth) after debonding to determine the failure mode. Therefore, after tube debonding, the tested surface (tooth / e-max) was inspected under an optical microscope (Scope Capture Digital Microscope, Guangdong, China) at magnification $49.5 \mathrm{X}$. The 
images were captured and transferred to a computer equipped with the Image analysis software (Image J 1.43U, National Institute of Health, USA) to evaluate ARI at the failed interfaces. The amount of adhesive remaining on the substrates surface was determined and scored with the original description of ARI ${ }^{(19)}$ as follows:

ARI $0=$ No adhesive remained on the substrates (e-max/tooth) and $100 \%$ of the adhesive on the tube.

ARI $1=$ less than half $(50 \%)$ of the adhesive remained on substrates.

ARI $2=$ more than half $(50 \%)$ of the adhesive remained on the substrates

ARI 3= All adhesive remained on the substrates with a clear imprint of the tube base.

ARI 4= Surface fracture of the substrates.

\section{Statistical analysis}

The data of surface roughness and shear bond strength test were statistically analyzed by using IBM SPSS Statistics for Macintosh, version 24.0 (IBM Corporation, Armonk, New York, USA). Data were checked for normality using Kolmogorov Smirnov test and Shapiro- test and were found to be normally distributed. Therefore, the obtained values were analyzed using two-way ANOVA, one-way ANOVA, and Turkey's post hoc analysis to explore the effect of interaction of different substrates with different surface treatments and type of adhesive on shear bond strength to metal tubes. The significance level for all of the analysis procedures was set at $\mathrm{P} \leq 0.05$. Kruskal-Wallis test was used to analyze statistical difference in ARI score for all adhesives.

\section{RESULTS}

\section{Surface Roughness(Ra) Measurement:}

Table (2) and figure (1) show the mean values and standard deviation (SD) for surface roughness measured in micron of the tested groups after different surface treatment. Results revealed a statistical significant difference between the all tested groups at $\mathrm{p}<0.001$. Tukey's Post-hoc test indicated that sandblasting group showed the statistical significant highest mean surface roughness, while the lowest mean surface roughness was recorded by the control group (no surface treatment).

TABLE (2): The mean, standard deviation (SD) and significance level for surface roughness in (micron) of all tested groups

\begin{tabular}{cccc}
\hline $\begin{array}{c}\text { Type of surface } \\
\text { treatment }\end{array}$ & Mean & \pm S.D. & $P$-value \\
\hline $\begin{array}{c}\text { Control group } \\
\text { (No surface treatment) }\end{array}$ & $0.154^{\mathrm{e}}$ & 0.02382 & \\
Sandblasting & $1.2635^{\mathrm{a}}$ & 0.19732 & \\
HF 9.6\% & $0.9156^{\mathrm{b}}$ & 0.150895 & $<0.001^{*}$ \\
HF 4.5\% & $0.6968^{\mathrm{c}}$ & 0.11463 & \\
Phosphoric acid 37\% & $0.3379^{\mathrm{d}}$ & 0.08295 & \\
\hline
\end{tabular}

Significance at $P \leq 0.05$, Different letters indicate statistically significant difference.

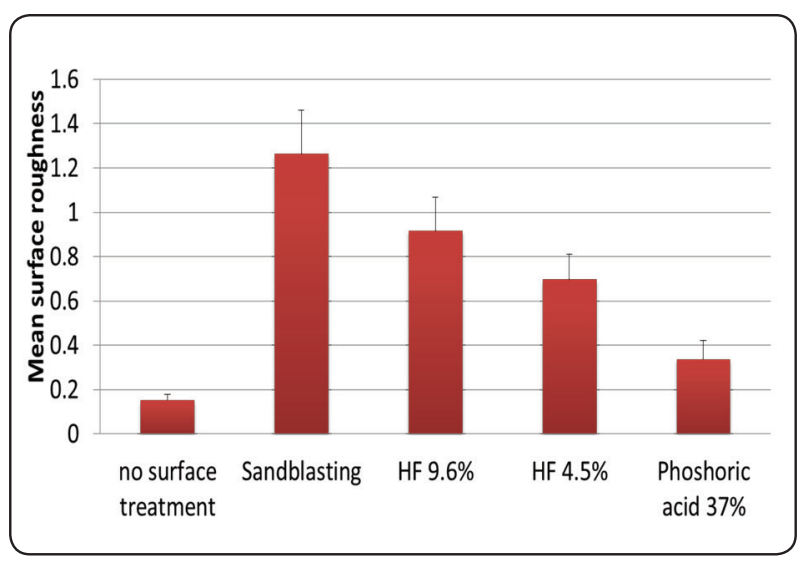

Fig. (1) Mean values and standard deviations of surface roughness of Lithium disilicate using the different surface treatments

\section{Surface and microstructural analyses:}

\section{Topographical analysis:}

The topographical characters of the tested groups scanned by AFM are illustrated in figures (2, A-E). Figure (2-A) shows 3D images of the control 
group and it reveals nearly uniform surface texture with multiple elevations and shallow valleys. Figure (2-B) shows 3D image of sandblasting group (I) which reveals broad elevated projections with multiple valleys. Concerning the e-max specimen which treated by hydrofluoric acid $9.6 \%$ (group II), the image shows more prominent sharpened and pointed peaks with deep valleys (spiky-like structure with an uneven ground) as showen in figure (2-C). However, specimens which treated with hydrofluoric acid $4.5 \%$ (group III), the 3D images show slightly broad elevated projections with shallow valleys (figure 2-D). Meanwhile, Figure (2-E) shows the 3D image of the phosphoric $37 \%$ group (IV) which reveals nearly smoothened elevations with very shallow valleys similar to control group.

\section{Microstructural analysis}

The microstructure of the all tested groups scanned by SEM is illustrated in figures (3, A-E). Figure (3-A) represents the microstructure of the control group which shows nearly uniform glazed surface at low magnification $500 \mathrm{X}(\mathrm{Ai})$, while at magnification 2000X (Aii) slight scratches and grooves were observed on the ceramic surface . While, figure (3-B i\&ii) shows numerous striations, depression and irregular grooves formed on the e-max surface due to sandblasting treatment (group I). Figure (3-C i\&ii) shows multiple and large microporosities which appear as small island (represented by arrows) (group III). However, in the group IV which treated with HF $4.5 \%$ the micro-porous become very small, with less number and separate from each other figure (3-D i\&ii). On the other hand, figure (3-E i\& ii) shows the microstructure of phosphoric acid group which shows very small fissures and superficial grooves with little microporosity at magnification 2000X (3 E ii) while at low magnification appear slight uniform surface (3 E i). Typical 2D SEM images of E-max ceramic surfaces of all the tested groups after different surface treatment are shown in figure (4; A-E).

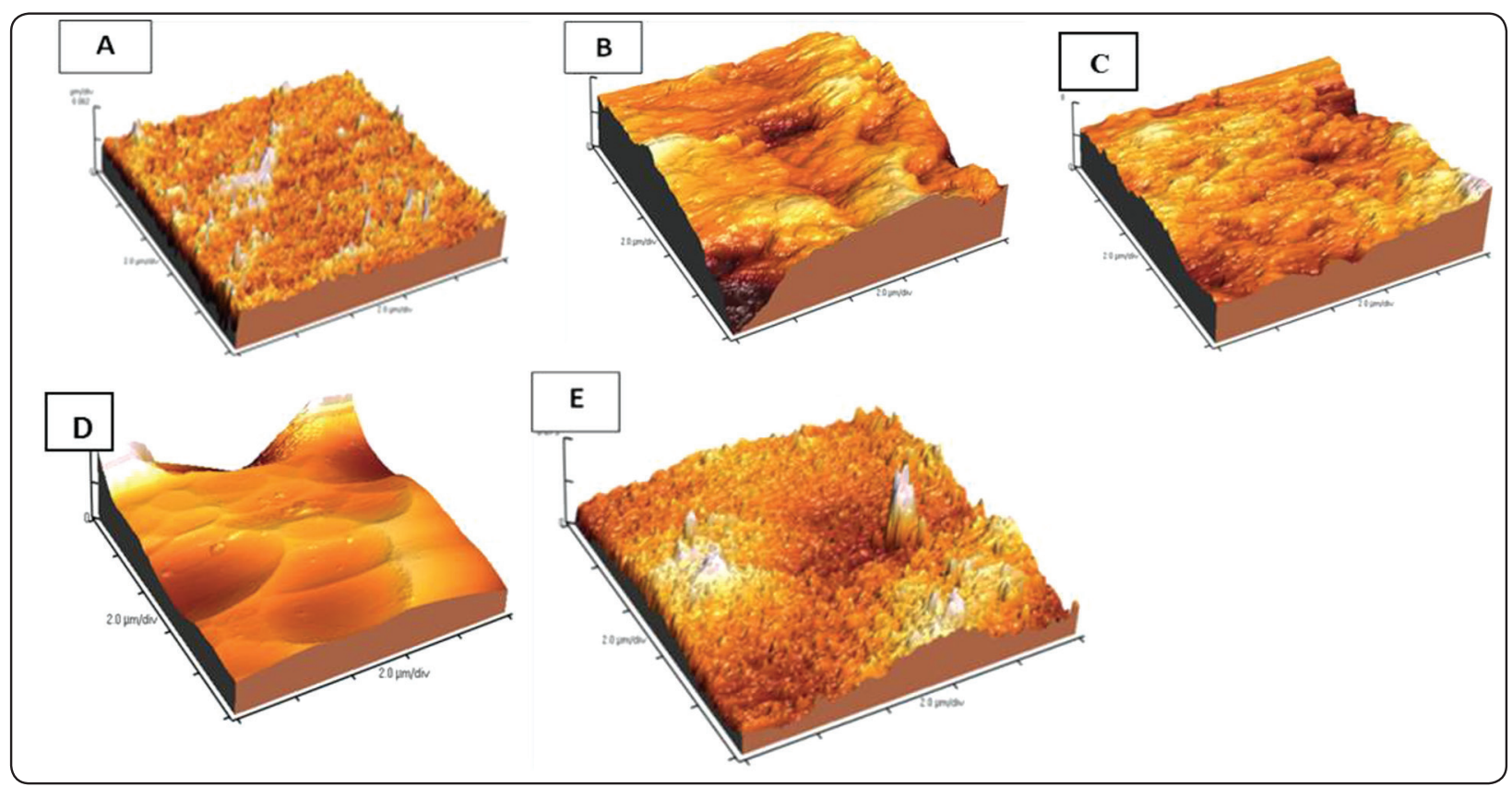

Fig. (2) The atomic force micrographs of e.max specimens of all tested group: (A) No surface treatment (GpI), (B) Sandblasting (GpII), (C) Hydrofluoric acid 9.6\%(GpIII), (D) Hydrofluoric acid4. 5\% (GpVI) and (E) Phosphoric acid 37\%(GpV) 


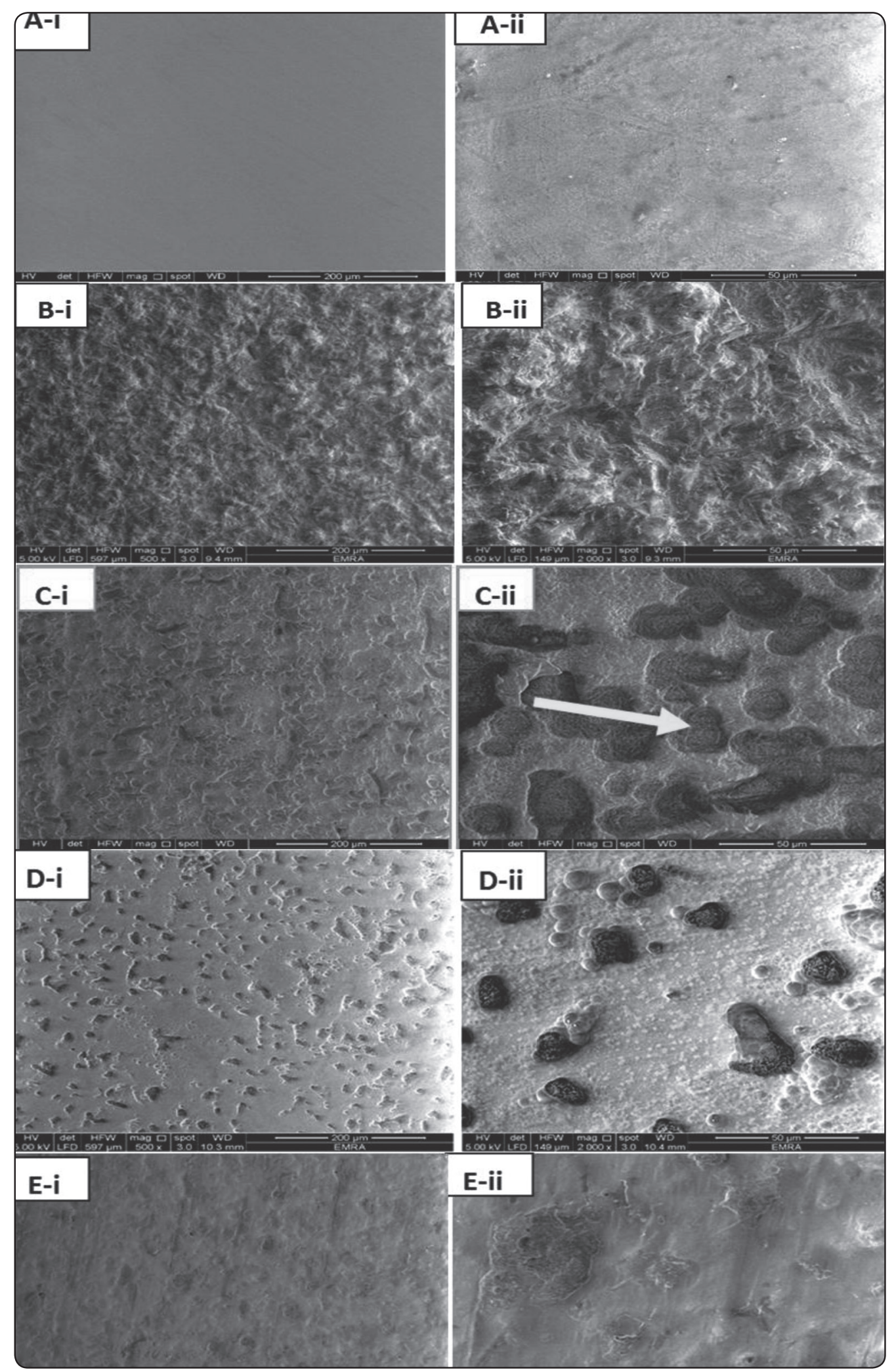

Fig. (3) SEM images of e-max ceramic surfaces of all the tested groups with two magnification (i) 500X (ii) 2000X. (A) No surface treatment ,(B) Sandblasting, (C) Hydrofluoric acid 9.6\%, (D) Hydrofluoric acid 5\% and (E) Phosphoric acid 37\% 


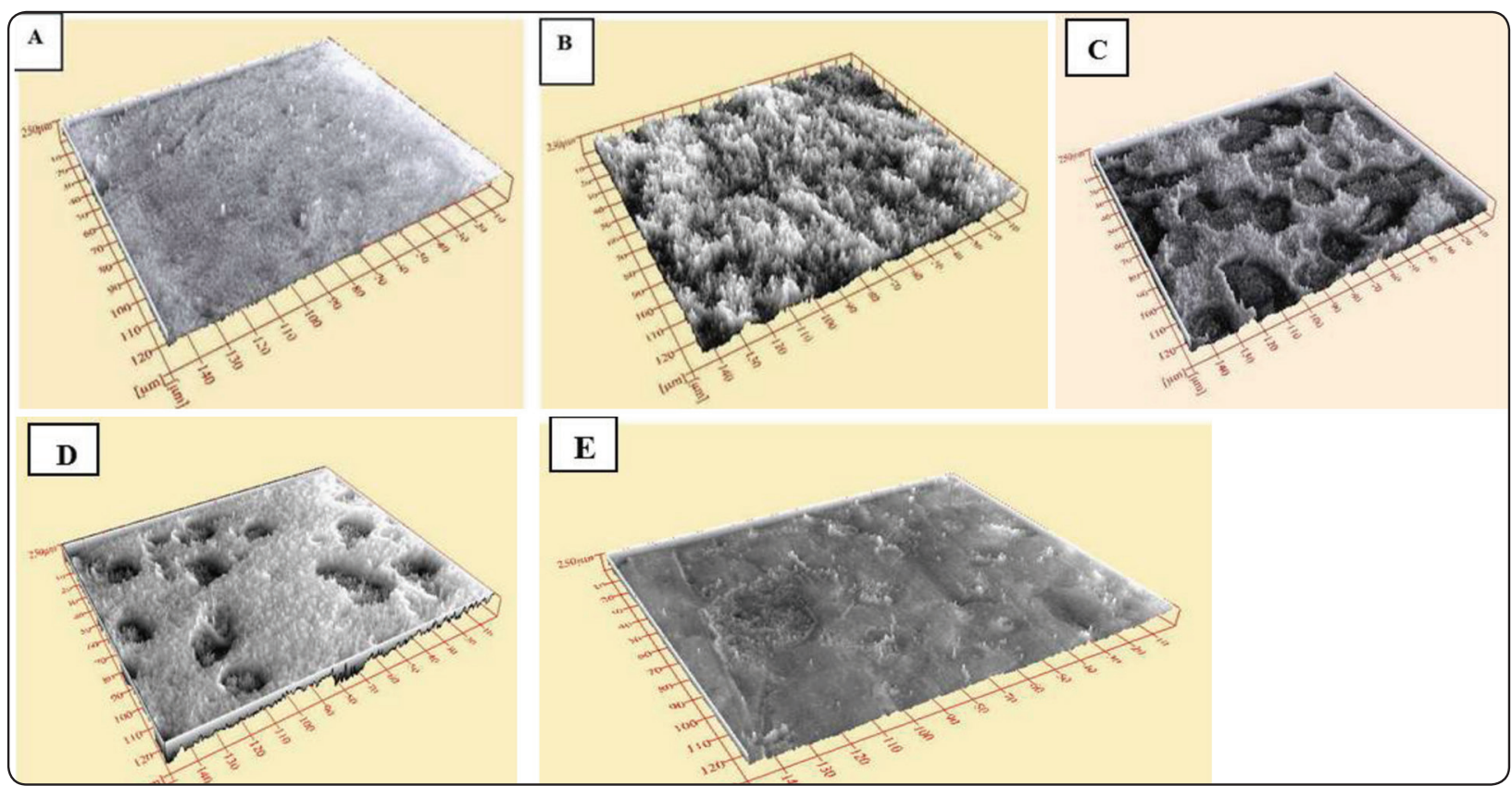

Fig. (4) SEM images (2D) of E-max ceramic surfaces of all the tested groups after different surface treatment: (A) No surface treatment, (B) Sandblasting, (C) Hydrofluoric acid 9.6\%,(D) Hydrofluoric acid 4.5\% and (E) Phosphoric acid 37\%

\section{Shear Bond Strength:}

The mean values of shear bond strength (MPa) and standard deviation (SD) of all tested groups are summarized in table (3) and are represented graphically in figure (5). There was significant difference in shear bond strength between different substrates with different surface treatments $(\mathrm{p}<0.001)$. Tukey's Post-hoc test was raveled that sandblasting group and hydrofluoric $9.6 \%$ group showed the statistical significant highest mean shear bond strength. However, by treating the e-max surface with $4.5 \% \mathrm{HF}$, phosphoric acid $37 \%$ and Enamel (phosphoric acid $37 \%$ ) the shear bond strength was recorded lower mean with no significant difference between them. On the other hand, the lowest mean shear bond strength was recorded by control group (no surface treatment).Regardless of the type of surface treatments, results showed there was no significant difference between types of adhesives used ( $>0.05$ ). Acorrding to Pearson product-moment correlation coefficient, there was strong positive correlation between roughness and shear bond strength $(\mathrm{r}=0.693)$ at $\mathrm{p}=0.0001$.

TABLE (3) The descriptive statistical of shear bond strength means values (MPa) and standard deviation (SD) of the different groups

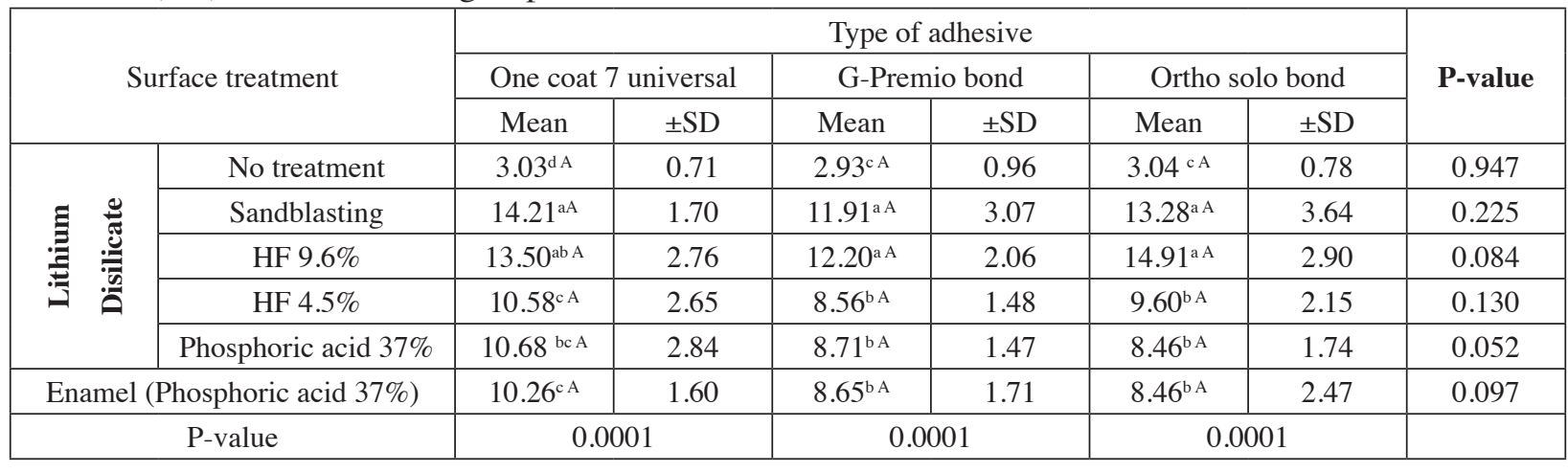

Significant at $P \leq 0.05$, Different small letters in the same column indicate statistically significant difference between surface treatments, Different capital letters in the same row indicate significant difference between the adhesive 


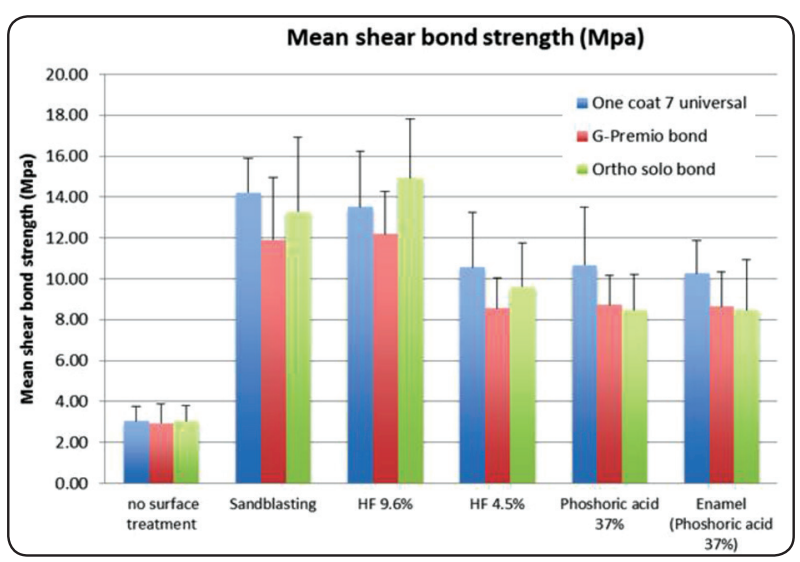

Fig. (5) Shear bond strengths (MPa) of all tested groups using the different adhesive

\section{ARI Distributions:}

The amounts of residual adhesives on the e-max and enamel surface of the tested groups as evaluated by the ARI scores are shown in table (4) and represented graphically in figure (6). Regardless of the adhesive used, results showed that sandblasting of the e-max surface exhibited mixed failure (score 0 and 2) with the higher prevalence of score $2(80 \%)$ indicating higher bond strength to the ceramic surface. However, by treating the surface with $4.5 \% \mathrm{HF}, 100 \%$ of the bonding failure was revealed as mixed failure with score 1 (figure 7-e), only, representing minute amount of adhesive remnants on the ceramic surface. Meanwhile adhesive failure (score 0) (figure 7-d) was recorded in the ceramic surface group treated with phosphoric acid, indicating a lower bond strength values. On the other hand, for enamel group, all adhesives recorded $60 \%$ up to $100 \%$ mixed failure with score 2 with the less prevalence for score 1 and 3 (figure 7-b). Nevertheless, no surface fracture was detected at any tested group except for enamel bonded with ortho solo adhesive.

TABLE (4) The descriptive statistical of the distributions and percentages of adhesive remaining on the e-max/teeth surface after debonding

\begin{tabular}{|c|c|c|c|c|c|c|c|}
\hline \multicolumn{8}{|c|}{ Adhesive Remenant Index(ARI) } \\
\hline \multicolumn{2}{|c|}{ Type of surface treatment } & Score 0 & Score 1 & Score 2 & Score 3 & Score 4 & P-value \\
\hline \multirow{3}{*}{$\begin{array}{l}\text { Control group } \\
\text { (no surface } \\
\text { treatment) }\end{array}$} & One coat 7 bond & 10 & 0 & 0 & 0 & 0 & \multirow{3}{*}{0.368} \\
\hline & G-Premio bond & 9 & 1 & 0 & 0 & 0 & \\
\hline & Ortho solo bond & 10 & 0 & 0 & 0 & 0 & \\
\hline \multirow{3}{*}{ Sandblasting } & One coat 7 bond & 1 & 0 & 1 & 8 & 0 & \multirow{3}{*}{0.0001} \\
\hline & G-Premio bond & 2 & 0 & 8 & 0 & 0 & \\
\hline & Ortho solo bond & 2 & 0 & 8 & 0 & 0 & \\
\hline \multirow{3}{*}{ HF $9.6 \%$} & One coat 7 bond & 2 & 0 & 8 & 0 & 0 & \multirow{3}{*}{0.0001} \\
\hline & G-Premio bond & 0 & 0 & 0 & 10 & 0 & \\
\hline & Ortho solo bond & 0 & 1 & 9 & 0 & 0 & \\
\hline \multirow{3}{*}{$\mathrm{HF} 4.5 \%$} & One coat 7 bond & 0 & 10 & 0 & 0 & 0 & \multirow{3}{*}{0.0001} \\
\hline & G-Premio bond & 1 & 9 & 0 & 0. & 0 & \\
\hline & Ortho solo bond & 0 & 10 & 0 . & 0 & 0 & \\
\hline \multirow{3}{*}{$\begin{array}{c}\text { Phoshoric acid } \\
37 \%\end{array}$} & One coat 7 bond & 8 & 0 & 2 & 0 & 0 & \multirow{3}{*}{0.191} \\
\hline & G-Premio bond & 6 & 0 & 2 & 2 & 0 & \\
\hline & Ortho solo bond & 9 & 10 & 0 & 0 & 0 & \\
\hline \multirow{3}{*}{$\begin{array}{c}\text { Enamel } \\
\text { (Phoshoric acid } \\
37 \%)\end{array}$} & One coat 7 bond & 0 & 0 & 10 & 0 & 0 & \multirow{3}{*}{.093} \\
\hline & G-Premio bond & 0 & 0 & 7 & 3 & 0 & \\
\hline & Ortho solo bond & 1 & 2 & 6 & 0 & 1 & \\
\hline
\end{tabular}

$A R I 0=$ No adhesive remained on the substrates (e-max/tooth). ARI $1=$ less than half of the adhesive remained on substrates. $A R I 2=$ more than half of the adhesive remained on the substrates ARI 3= All adhesive remained on the substrates with a clear imprint of the bracket base. ARI 4= Surface fracture of the substrates. 


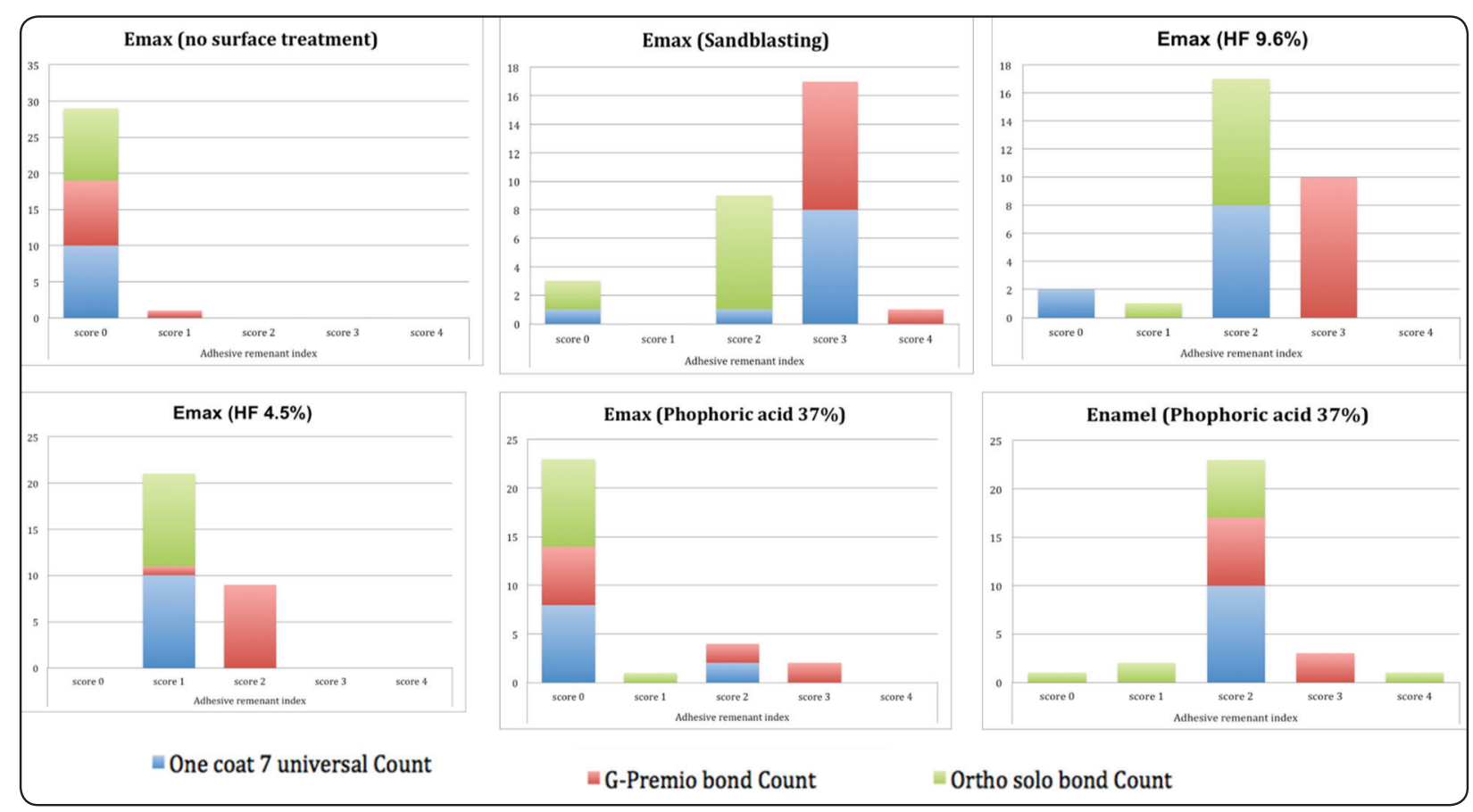

Fig. (6) The ARI distribution in each surface treatment using different adhesive.

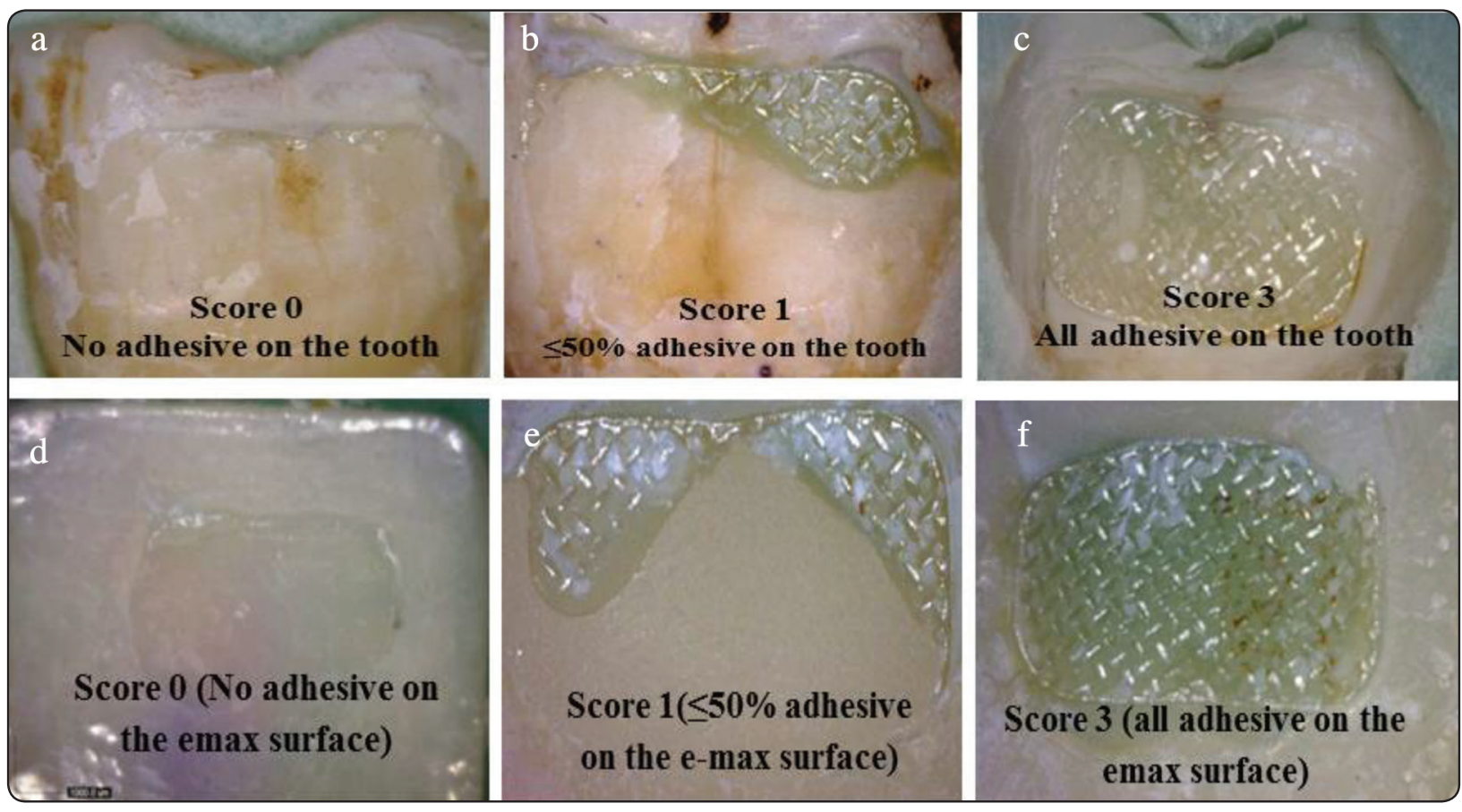

Fig. (7) The different ARI scores after molar tube debonding under optical microscope (X49.5) 


\section{DISCUSSION}

Raising the esthetic demands among dental patients prompts the crisis of lithium disilicate crowns as an efficient alternative. IPS e-max CAD belongs to this category of glass-ceramic which has higher mechanical properties contrasted with the conventional feldspathic or leucite-strengthened glass ceramics. Ceramic restorations can treat some esthetic problems, and others need further orthodontic intervention. ${ }^{(20)}$ Nowadays, the use of buccal tubes in the orthodontic treatment is slowly replacing molar bands because these tubes are more convenient for both the clinician and patient. Also, they eliminate the additional appointment time for placement of separators, the post-orthodontic space in between the molars and provide easier maintenance of gingival health. ${ }^{(21)}$

The long-term survival of any orthodontic treatment relies on the success of a reliable bond between the orthodontic appliance and the tooth or any other substrate including ceramics.

In this study different surface treatment methods were used; mechanically by sandblasting and chemically by using hydrofluoric acid with two concentrations $(9.6 \%, 4.5 \%)$ or $37 \%$ orthophosphoric acid. These methods have been chosen to treat the ceramic surface as they are the most satisfactory methods used in the clinic. However, every method has limitations and inherent risk. ${ }^{(22)}$ Thus, this study aimed for evaluating the shear bond strength of orthodontic molar tubes to Lithium Disilicate after using the previously mentioned surface treatment protocols.

In the current study, three universal bonding agents, One Coat 7, G-Premio bond, and Ortho Solo were used, due to their known exceptional bond strengths to enamel and dentine. ${ }^{(23)}$ However, the literature is lacking information about their bonding performance with lithium disilicate glass ceramics. They contain MDP monomer which creates a strong bond with composite, metal and ceramic surfaces as claimed by the manufacturer. ${ }^{(12)}$. G-Premio bond is a universal, $8^{\text {th }}$ generation of bonding agent that is perfectly adapted to all direct restorations and can also be used to repair indirect restorations without the use of a primer. ${ }^{(24)}$ While, One Coat 7 universal is a light-cured, one-component bonding agent used with the self-etching, selective etch or etch and rinse technique for adhesive restorations. It is characterized by its low-evaporation formula as no volatile acetone-based solvents that can quickly evaporate, and it contains nanofillers that could improve its mechanical properties and bond strength. ${ }^{(25)}$ Furthermore, Ortho Solo is a universal bonding agent that has hydrophilic property thus it is moisture tolerant for optimal and reliable orthodontic bonding. The manufacturer claimed that it has a unique property designed to act as stress and shock absorber, and prevent crack propagation that can lead to bond failure. ${ }^{(26,27)}$

All tested specimens were subjected to thermocycling at $5-55{ }^{\circ} \mathrm{C}$ for 3000 cycles, stored in distilled water at $37^{\circ} \mathrm{C}$, in order to simulate the moisture and temperature changes in the oral environment. According to Schaneveldt and Foley (2002) ${ }^{(28)}$, thermocycling of specimens was essential to consider the durability of the bond. The number of employed cycles would confirm adequate shear bond strength. In order to improve the bond strength between e-max ceramic and resin composite, silane coupling agents was used on the ceramic surface. The silane coupling agents contain bifunctional groups, which promotes chemical interaction between the silica in the glass phase of ceramics and the methacrylate groups of the resin through siloxane bonds that improves also the durability and moisture resistance. ${ }^{(29-31)}$

Regardless of the type of adhesive used, the results showed that the sandblasting group recorded higher bond strength than the other groups (Table 3 \& Figure 5). This result was confirmed by the AFM images of the sandblasting group (figure 2) which revealed a more roughened surface than those of the other groups. This could be referred to the severe irregularity created by sandblasting leads 
to an increase in surface free energy consequently the bond strength was increased. ${ }^{(32,33)}$ Additionally, surface roughening increased the surface area that allow extra potential retention sites in which the adhesive cement can easily be interlocked to act effectively in enhancing the shear bond strength. ${ }^{(34)}$ The obtained results were in agreement with others who created rough surface for mechanical retention via removal of the glazed layer by abrasion process. ${ }^{(35)}$ On the other side, sandblasting induced damage in the e-max surfaces and partially destroyed the glass matrix which may interfere with adequate bonding.

HF with a concentration of $9.6 \%$ exhibited high shear bond strength (Table 3, Figure 5). This could be explained by the ability of HF acids to attack the glassy phase of the ceramic, dissolving the surface to the depth of a few micrometers, and consequently a lithium disilicate crystal was protruded from the glassy matrix, ${ }^{(36 \& 37)}$ the resultant-altered topography increased the surface area for micromechanical bonding with resin composites ${ }^{(35,36)}$

Meanwhile, specimens etched with $4.5 \% \mathrm{HF}$ acid showed significantly lower bond strength values than those etched with $9.6 \% \mathrm{HF}$ acid. This could be attributed to the higher concentration of HF acid that would dissolve much of the glassy matrix away, and more crystals are projected so the ceramic surface became progressively more irregular and rough in appearance. ${ }^{(37)}$ These results were in consistence with those obtained by Caparroso et al, $(2014)^{(\mathbf{1 0})}$. Moreover, SEM analysis of the various treated surfaces; Figure ( $3 \& 4)$, verified the obtained results and showed less topographic changes with superficial groove and fissures for the $4.5 \%$ HFacid etched specimens.

The time of exposure to HF should be considered, the specimens in the present study were subjected to HF acid for $3 \mathrm{~min}$ in order to imitate its intraoral application. When HF is used longer than 3 min, although intensive protective measures are taken, the possible side effect of acid leakage into soft tissues might occur. ${ }^{(9 \& 39)}$
On the other hand, bond strength achieved after using phosphoric acid has been found to be almost lower than that with $9.6 \%$ hydrofluoric acid. This may be attributed to its slight roughening effect on the ceramic surface as shown by AFM and SEM image in Figure 2,3 and 4 and incomplete removal of the glazed layer. While the bond strength achieved after using phosphoric acid has been found to be almost equal to that with $4.5 \%$ hydrofluoric acid this might be explained by the fact that both acids have a similar effect on ceramic surface, this in agreement with faltermeier, etal 2013, Addison etal, Guruprasada etal.$^{(40-42)}$ On the contrary, another study showed that phosphoric acid is inferior compared to $4.5 \%$ hydrofluoric acid in creating the micro-irregularities for the effective bonding between the ceramic surface and resin cement. This controversial may be attributed to the difference in the type of ceramic used and/or etching duration. ${ }^{(17,43)}$ Though, the inability of $37 \%$ phosphoric acid to etch the ceramic surface, it produced acceptable bond strength. This could be attributed to the ability of phosphoric acid to neutralize the alkalinity of the adsorbed water layer present on ceramic restorations in the mouth and thereby improve the chemical reactivity of the silane primer that was subsequently applied. ${ }^{(7 \& 44)}$ Another explanation according Augusti et al 2015, ${ }^{(33)}$ the satisfactory SBS values obtained after using phosphoric acid might be attributed to using the silane and the functional phosphate monomer MDP which present in the composition of the universal adhesive.

Regardless of the type of surface treatment, no significant difference in shear bond strength was observed in the current study among different types of the used adhesives (Table 3, Figure 5). It is porobale due to the domination of the micromechanical bonding mechanism rather than the chemical one. This assumption was suggested because the used adhesives were dissimilar in their compositions.

Moreover, results of the current study showed that all the investigated bonding systems showed satisfactory adhesive strength values to enamel 
$(8.46 \pm 2.47--10.26 \pm 1.6 \mathrm{MPa})$ which is greater than those required for clinical application $(5.9-7.8 \mathrm{MPa})$ according to Grover et al. ${ }^{(45)}$ Other researchers stated that the clinically accepted bond strength values for conventional adhesive systems to porcelain lie between $(6-13 \mathrm{MPa})$ to prevent cohesive porcelain fracture. ${ }^{(43)}$

The bond failure of brackets represents a significant problem during the period of orthodontic therapy. In fact, at the end of the treatment the brackets must be removed without residue and without causing damage to the enamel or prosthetic crowns, such as cracks or chipping. ${ }^{(46)}$ Even, Grover et al., (2014) (45) stated that it is better to have a repeatable bond failure rather than an irreversible enamel tear or crack. However, if it became necessary to choose between easier debonding and optimal strength, the latter would undoubtedly be the choice of most clinicians. ${ }^{(16)}$

It has been reported that there is a strong correlation between the mean bond value and the failure mode, where higher bond strength values are correlated with high number of cohesive failures. ${ }^{(45)}$ In this study, the control specimens and those treated with phosphoric acid recorded about $90 \%$ of debonding interfaces were mainly adhesive failure at e-max/resin interface scored 0 (no adhesive left on the e-max surface), while the remaining $10 \%$ were scored 1 (less than $50 \%$ of adhesive on the e-max surface); (Table $3 \&$ Figure $7 \mathrm{~d} \& \mathrm{e})$. As previously mentioned this could be attributed to the weak bonding between the adhesive and the e-max surface reported in these two groups. It has been proven that adhesive failure during debonding is preferred to cohesive failure, because the latter may lead to ceramic fracture, if the bond strength between the ceramic and composite resin is $>13 \mathrm{MPa}$, the risk of cohesive fracture increases. ${ }^{(47)}$

According to ARI analysis, the sandblasting and HF 9.6\% (Gp2 and Gp3), 80\% of the debonded interfaces were recorded as a mixed failure (Score 2 and 3) (Table 3\& Figure 6). This indicates better cement/e-max adhesion attributed to rougher and cleaner surface together with higher surface energy that was obtained by sandblasting or $9.6 \% \mathrm{HF}$ acid which in turn improved micro retention of the cement to the ceramic surface. This finding could also indicate that more time is needed to remove the remaining adhesive from the ceramic surface treated by $9.6 \% \mathrm{HFand}$ sandblasting

On the other hand, the results of the ARI showed an inhomogeneous distribution in the score of the used bonding agents with enamel. One Coat 7 bond and G-Premio bond revealed $100 \%$ and $70 \%$ respectively mixed failure with Score 2 denoting large amounts of adhesive remnants on the tooth. This might be interpreted by the type of the formed bond. The mechanical interlocking occurred due to adhesive penetration to the etched enamel was stronger than the chemical bonding of MDP with the composite; thus, more adhesive residue was present on the enamel surface. While, Ortho Solo bond showed less amount of adhesive remaining on enamel surface (Figure; 7a), making it more easy to be debonded during SBS leaving minute adhesive remnants on the surface, therefore Ortho Solo bond is more safer for clinical use.

As the current study showed that surface treatment of lithium disilicate greatly affected its shear bond strength with the orthodontic molar tubes, therefore, the null hypothesis of this study is not accepted.

\section{CONCLUSIONS}

Within the limitations of the present investigation, the following can be concluded:

1. Shear bond strength was governed by the surface roughness which subsequently controlled by the surface treatment modalities and not by the adhesives' types.

2. Hydrofluoric $4.5 \%$ and phosphoric acid $37 \%$ are recommended techniques for reliable bond strength between metal tubes and disilicate lithium ceramic. 
3. An increased hydrofluoric acid concentration catastrophically alters the surface microstructure and detrimentally destroys the ceramic surface.

4. The adhesive system commonly used by orthodontists; Ortho Solo, can be substituted competently and efficiently by other bonding systems; One Coat 7 bond and G-Premio, used in restorative dentistry.

\section{REFERENCES}

1. Albakry M, Guazzato M, Swain MV. Biaxial flexural strength, elastic moduli, and x-ray diffraction characterization of three pressable all-ceramic materials. J Prosth Dent. 2003; 89(4): 374-80.

2. Belli R, Geinzer E, Muschweck A, Petschelt A, Lohbauer U. Mechanical fatigue degradation of ceramics versus resin composites for dental restorations. Dent Mat. 2014; 30(4): 424-32.

3. Viskic J, Jokic D, Jakovljevic S, Bergman L, Ortolan SM, Mestrovic S, etal. Scanning electron microscope comparative surface evaluation of glazed lithium disilicate ceramics under different irradiation settings of Nd:YAG and Er:YAG lasers. Angle Orthod. 2018; 88 (1):75-81.

4. Newman SM, Dressler KB, Grenadier MR. Direct bonding of orthodontic brackets to esthetic restorative materials using a silane. Am J Orthod. 1984; 86:503-6.

5. Schmage P, Nergiz I, Herrmann W, Ozcan M. Influence of various surface-conditioning methods on the bond strength of metal brackets to ceramic surfaces. Am J Orthod Dentofac Orthop. 2003; 123:540-6.

6. Zachrisson Y, Zachrisson BU, Büyükyilmaz T. Surface preparation for orthodontic bonding to porcelain. Am J Orthod Dentofac Orthop. 1996; 109:420-30.

7. Kukiattrakoon B, Samruajbenjakul B. Shear bond strength of ceramic brackets with various base designs bonded to aluminous and fluorapatite ceramics. Eur J Orthod. 2010; 32:87-93.

8. Meng X, Yoshida K, Atsuta M. Microshear bond strength of resin bonding systems to machinable ceramic with different surface treatments. J Adhes Dent 2008;10:189-196.

9. Cevik P, Karacam N, Eraslan O, Sari Z. Effects of different surface treatments on shear bond strength between ceramic systems and metal brackets. J Adhes Sci Technol.2017; 31(6): 1105-15.

10. Caparroso CB, Latorre F, Arroyave LJ, Grajales CA, Maria $\mathrm{V}$, Piedrahita $\mathrm{M}$. In vitro evaluation of the effect of hydrofluoric acid concentration and application time on adhesion to lithium disilicate. Rev Fac Odontol Univ Antioq. 2014; 26: 62-75.

11. Aida M, Hayakawa T, Mizukawa K. Adhesion of composite to porcelain with various surface conditions. J Prosth Dent. 1995; 73:464-70.

12. Kalavacharla VK, Lawson NC, Ramp LC, Burgess JO. Influence of Etching Protocol and Silane Treatment with a Universal Adhesive on Lithium Disilicate Bond Strength. Oper Dent. $2015 ; 40(4): 372-8$

13. Zakir M, Ashraf U, Tian T, Han A, Qiao W, Jin X, et al.The role of silane coupling agents and universal primers in durable adhesion to dental restorative materials - a review . Curr Oral Health Rep. 2016; 3(3):244 -53.

14. Matinlinna J P, Lung CY K , Tsoi J KH. Silane adhesion mechanism in dental applications and surface treatments: A review. Dent Mat. 2018; 34(1):13-28.

15. Lestrade AM, Ballard RW, Xu X, Yu Q, Kee EL, Armbruster PC. Porcelain surface conditioning protocols and shear bond strength of orthodontic brackets. Aust Orthod J. 2016; 32:18- 22.

16. Pannes DD, Bailey DK, Thompson JY, Pietz DM. Orthodontic bonding to porcelain: a comparison of bonding systems. J Prosthet Dent. 2003; 89 (1):66-9.

17. Grewal Bach GK, Torrealba Y, Lagravere MO. Orthodontic bonding to porcelain: a systematic review. Angle Orthod. 2014; 84:555-60.

18. Blakey R, Mah J. Effects of surface conditioning on the shear bond strength of orthodontic brackets bonded to temporary polycarbonate crowns. Am J Orthod Dentofac Orthop. 2010; 138(1): 72-8.

19. Artun J, Bergland S. Clinical trials with crystal growth conditioning as an alternative to acid-etch enamel pretreatment. Am J Orthod Dentofac Orthop. 1984; 85(4): 333-40.

20. Daou EE. Esthetic Prosthetic Restorations: Reliability and Effects on Antagonist Dentition. Open Dent J. 2015;9: 473-81.

21. Purmal K, Alam MK, Sukumaran P. Shear bond strength of orthodontic buccal tubes to porcelain. Dent Res J. 2013; 10(1):81-6.

22. Abu Alhaija E, Al-Wahadni A. Shear bond strength of orthodontic brackets bonded to different ceramic surfaces. Eur J Orthod. 2007; 29(4):386-89.

23. Zope A, Zope-Khalekar Y, Chitko SS, Kerudi VV, Patil HA, Bonde PV, et.al. Comparison of Self-Etch Primers with Conventional Acid Etching System on Orthodontic Brackets. J Clin Diagn Res. 2016;10(12):ZC19-ZC22 
24. https://www.gceurope.com/products/gpremiobond/

25. https://www.coltene.com/products/restoration/bondings/ one-coat/one-coat-7-universal/

26. https://ormco.com/products/ortho-solo/

27. Klocke A, Shi J, Kahl-Nieke B, Bismayer U. Invitro investigation of indirect bonding with a hydrophilic primer. Angle Orthod. 2003; 73 (4): 445-50.

28. Schaneveldt S, Foley TF. Bond strength comparison of moisture-insensitive primers. Am J Orthod Dentofacial Orthop. 2002;122: 267-73

29. Lung CY, Matinlinna JP. Aspects of silane coupling agents and surface conditioning in dentistry: An overview. Dent Mater. 2012; 28: 467-77.

30. Ozcan M, Volpato CA. Surface conditioning protocol for the adhesion of resin-based materials to glassy matrix ceramics: How to condition and why? J Adhes Dent. 2015; 17: 292-293.

31. Turkkahraman H, Kucukesmen HC. Porcelain surfaceconditioning techniques and the shear bond strength of ceramic brackets. Eur J Orthod. 2006; 28:440-443.

32. Kurtulmus-Yilmaz S, Cengiz E and Ongun S. The Effect of Surface Treatments on the Mechanical and Optical Behavior s of CAD/CAM Restorative Materials. J of Prosthodontics . 2018;10(5):1-8

33. Augusti D, Gabriele A, Francesca C, Dino R. Does Sandblasting Improve Bond Strength between Nano-ceramic Resin and Two Different Luting Composites? Bioceram Dev Appl. 2015;5:086.

34. Keshvad A, Hakimaneh SMR. Microtensile Bond Strength of a Resin Cement to Silica-Based and Y-TZP Ceramics Using Different Surface Treatments. J Prosthodont. 2018; 27(1):67-74.

35. Ramakrishnaiah R, Alkheraif AA, Divakar DD, Matinlinna JP, Vallittu PK. The Effect of Hydrofluoric Acid Etching Duration on the Surface Micromorphology, Roughness, and Wettability of Dental Ceramics. Int J Mol Sci. 2016; 17: 822

36. Chen JH, Matsumura H, Atsuta M. Effect of etchant, etching period, and silane priming on bond strength to porcelain of composite resin. Oper Dent 1998;23:250-257

37. Prochnow C, Venturini AB, Grasel R, Bottino MC, Valandro LF. Effect of etching with distinct hydrofluoric acid concentrations on the flexural strength of a lithium disilicate-based glass ceramic. J Biomed Mater ResB Appl Biomater 2017; 105:885-891

38. Xiaoping L, Dongfeng R., Silikas, N. Effect of etching time and resin bond on the flexural strength of IPS e.max Press glass ceramic. Dent. Mater. 2014; 30: 330-336.

39. Wang C, Zeng J, Wang S, Yang Z, Huang Q, Chen P et al. Influence of surface treatments on the shear bond strength of orthodontic brackets to porcelain. Appl Surf Sci. 2008;255:416-418.

40. Faltermeier A, Reicheneder C, Götzfried P, Proff P. Bonding orthodontic ceramic brackets to ceramic restorations: Evaluation of different surface conditioning methods. Mat Sci Appl. 2013; 4(7):10-14.

41. Addison O, Fleming GJ, Marquis PM. The effect of thermocycling on the strength of porcelain laminates veneer (PLV) materials. Dent Mater 2003; 19:291-297.

42. Guruprasada, Rivankar N, Dhiman RK, Viswambaran M. Evaluation of the effect of surface preparation using phosphoric acid and luting cement on the flexural strength of porcelain laminate veneering material. Med J Armed Forces India. 2015; 71:299-305.

43. Thurmond JW, Barkmeier WW, Wilwerding TM. Effect of porcelain surface treatments on bond strengths of composite resin bonded to porcelain. J Prosthet Dent. 1994;72, 355-359.

44. Mehmeti B, Haliti F, Azizi B, Kelmendi J, Iljazi-Shahiqi D, Jakovljević S et al. Influence of different orthodontic brackets and chemical preparations of ceramic crowns on shear bond strength. AMJ 2018;11(2):107-112.

45. Grover S, Bhardwaj M, Khattri S, Autar R, Pradhan KL, Koul R. A. comparison of shear bond strength and debonded surface characteristics of three orthodontic bonding resin adhesive systems: An in-vitro study. Orthod Cyber J. 2014;1.

46. Hellak A, Ebeling J, Schauseil M, Stein S, Roggendorf M, and Korbmacher Steiner H. Shear Bond Strength of Three Orthodontic Bonding Systems on Enamel and Restorative Materials. BioMed Research International. 2016; 8:1-10

47. Zarif Najafi H, Oshagh M, Torkan S, Yousefipour B, Salehi R. Evaluation of the effect of four surface conditioning methods on the shear bond strength of metal bracket to porcelain surface. Photomed Laser Surg. 2014;32(12):694-9. 